\title{
An Assessment of the Scholarship of Teaching and Learning in Public Administration from 2009-2013
}

\author{
Rebekkah Stuteville, PhD \\ Associate Professor of Public Administration \\ Park University \\ Eric Click, PhD \\ Associate Professor of Public Administration \\ Park University
}

The acceptance of the Scholarship of Teaching and Learning (SoTL) as a legitimate

form of scholarly investigation and the shape that it takes in post-secondary education are inherently discipline-specific. This paper examines how the character and heritage of public administration influence the acceptance of SoTL, and the form

that it takes. It argues that the applied nature of public administration and its interdisciplinary character have influenced SoTL in the discipline. This study concludes systematic self-reflection by disciplines may be needed to identify potential factors that limit the acceptance and/or direction of SoTL in a discipline.

The Scholarship of Teaching and Learning (SoTL) is a form of scholarly inquiry into teaching and learning that is "systematically assessed," evaluated for its "effectiveness on learning," and is subjected to peer review (Hamann, Pollock \& Wilson, 2009, p. 730). Thus, SoTL is of potential interest to anyone who is concerned with the effectiveness of teaching and student learning in the classroom. In spite of its broad applicability to a number of disciplines, SoTL is an academic investigation model that must be tailored and integrated into each specific discipline. As explained by Huber and Morreale (2002), "Teaching and learning are, in the end, not the same across the fields" (p. 2). SoTL derives its legitimacy and substance from each academic discipline. SoTL is "context-specific" (McKinney, 2013, p. 2). The degree to which SoTL is accepted varies by academic discipline, and the form that it takes is shaped by each discipline.

This research explores SoTL from the perspective of one discipline-public administration. It seeks to determine whether the character and heritage of public administration influence the acceptance of SoTL and the form that it takes in the discipline. The paper begins with an explanation of the complexities of defining public administration as an academic discipline and how this affects SoTL. Next, the current direction of SoTL in public administration is analyzed through an examination of abstracts published in The J ournal of Public Affairs Education (JPEA). The paper includes a discussion of how contemporary trends in SoTL reflect longstanding issues and conflicts in public administration. It concludes with an examination of how this case study may inform other disciplines outside of public administration.

\section{Review of the Literature}

There is general agreement that SoTL is grounded in the academic disciplines (Hamman et al., 2009, p. 731). Huber and Morreale (2002) explain that

Each discipline has its own intellectual history, agreements, and disputes about subject matter and methods that influence what is taught, to whom, when, where, how and why. Each has a set of traditional pedagogies, such as lab instruction and problem sets in the sciences, and its own discourse of reflection and reform. (p. 2) 
The academic framework that defines each discipline influences SoTL in a number of ways which include: (a) The acceptance of SoTL by a discipline and (b) The expression of SoTL within the discipline.

Researchers have studied and identified some of the disciplinary variations regarding the acceptance of SoTL. For example, Witman and Richlin (2007) examine the extent to which the humanities, natural sciences, professions, and social sciences have integrated SoTL through conferences and publications. Public administration is not often identified in these discipline-specific discussions of SoTL, and, at best, public administration is considered a subset within political science in these conversations.

In some respects public administration presents a special case for SoTL since the discipline has struggled to define itself, and it is often positioned between political science and the management sciences. Public administration, however, does not fit neatly into the discipline of political science, nor does is fall exclusively into the domain of the management sciences. It defies disciplinary definition due to its interdisciplinary nature, which draws upon areas such as sociology, economics, and social psychology (Waldo, 1984, p. xix) as well as law, economics, anthropology, criminology, social work, medicine, engineering, and logistics (Shafritz, Russell, \& Borick, 2013, p. 21). As public administration theorist Dwight Waldo famously explained, public administration is an '“enterprise' [that] contains many facets, perspectives, interests, and methodologies, and it is eclectic, experimental, and open-ended in addressing the problems of an untidy, swiftly changing world" (as cited in Fry \& Raadschelders, 2014, p. 421).

The scholarship of teaching and learning within public administration reflects what Rutgers refers to as the discipline's "identity crisis" (Rutgers, 2010, p. 1). Within the field, the acceptance of SoTL is somewhere in between political science and management. The field is more accepting of SoTL than political science, but it has not embraced SoTL as fully as the management sciences.

Political science is on the more conservative end of the continuum of acceptance, and it was relatively slow to adopt SoTL when compared to other social sciences (Hamman et al., 2009, p. 729). According to Reeher, the "professionalism and drive toward professionalism [in political science] have been marked by aspects that suggest some particular tensions for the scholarship of teaching and learning and those who are most concerned about it" (as cited in Clarke et al., 2002, p. 226). Reeher attributes the drive to professionalize to political science's need for legitimacy and funding until the 1950s (as cited in Clarke et al., 2002).

Like political science, public administration struggled with professionalization and legitimacy, which may constrain its acceptance of the scholarship of teaching and learning. Public administration is still wrestling with professionalization, and there is not agreement on whether or not it meets the standards of a profession. On the one hand, scholars argue that public administration meets the core requirements of professionalization, which include a "body of academic and practical knowledge ... . [and] standard of success . . . [concerned with] serving the needs of society" and "a system of control over the professional practice" (Shafritz et al., 2013, p. 22). On the other hand, scholars and practitioners still debate the two "professional touchstones"-acceptance of the same basic methodologies and literature (Goodin \& Klingemann, 1996, pp. 14-15)in public administration. Public administration's quest for legitimacy and acceptance as a profession may make it more reluctant than other disciplines to embrace SoTL.

In contrast to political science, management sciences were early adopters of SoTL. As early as 1975, a newsletter was published on the teaching of organizational behavior (Bilimoria \& Fukami, 2002, p. 126). The acceptance of SoTL in management has continued to grow through the Academy of Management's Education and Development Division, multiple management-related journals for the scholarship of teaching and learning, and books on management education (pp. 126-127). Bilimoria and Fukami (2002) argue that one reason why SoTL has thrived in the management sciences is that there is 
a fundamental synergy between the content of our discipline and the substance of the scholarship of teaching and learning. Perhaps more than most disciplines, management is one in which how teachers teach and the tools they use closely mirror important aspects of what they teach about the nature and functioning of the phenomena. (p. 129)

Like the management sciences, public administration is an applied science, which may lend itself to the same type of "synergy between the content of [the] discipline and the substance of the scholarship of teaching and learning" (Bilimoria \& Fukami, 2002, p. 129). The relatively early acceptance by public administration of SoTL as a form of scholarly inquiry, when compared to political science, is evident in the creation of the Journal of Public

The degree to which SoTL has been accepted by the discipline is grounded in public administration's character and heritage.

Affairs Education (Witman \& Richlin, 2007) in 1994.

This journal continues to maintain a solid reputation in the field. However, the Journal of Public Affairs Education is still one of the few journals dedicated to the scholarship of teaching and learning in public administration.

Public administration appears to have accepted SoTL more readily than political science, but it has not been as aggressive as the management sciences in creating additional forums for disseminating the scholarship of teaching and learning. As with political science, public administration's search for professionalization has restrained its acceptance of SoTL. However, its status as an applied science moves it closer to the management sciences.

The degree to which SoTL has been accepted by the discipline is grounded in public administration's character and heritage. The following analysis of abstracts from the Journal of Public Affairs Education (2009-2013) will demonstrate that the discipline's history and debates have also influenced the form that SoTL has taken. The next section will explore how the academic framework of public administration has influenced the expression of SoTL in the discipline.

\section{Method}

The purpose of this case study investigation is to examine the acceptance of SoTL in public administration, determine the form of SoTL within the discipline, and assess what the current trends tell us about the field. In order to assess the form and trends of SoTL in public administration, the investigators engaged in a multi-step process.

Case studies are utilized in answering "how" and/or "why" questions, particularly when the researcher has minimal to no control over events and the primary focus is on contemporary phenomenon within a reality context (Yin, 2003). These types of case studies are often explanatory in nature, complemented by exploratory and descriptive research. In general, the how and why require researchers to follow operational links over time, instead of isolated occurrences (Yin, 2003, pp. 1-6).

The investigators began by establishing the possible categories for research in the areas of teaching and learning. The categories were derived by evaluating the definitions of SoTL from the University of Queensland (n.d.), the University of Central Florida (2004), the Carnegie Foundation for the Advancement of Teaching, Indiana University at Bloomington, Western Carolina, and Illinois State University (as cited in University of Central Florida, 2004). The review of definitions yielded six possible SoTL categories: Instructional Approaches/Pedagogy, Learning Processes, Curricula, Learning Materials, Assessments, and Other. The investigators did not establish pre-determined definitions for each category; however, as part of the classification process, the following definitions were created by the authors. One, Instructional Approaches/Pedagogy are approaches to delivering curriculum. Examples of subjects included in this category are online education, 
simulations, experiential learning, and service learning. Two, Learning Processes are research on how people learn. Examples of subjects included in this category are learning values and cognitive skills. Three, Curricula are the academic content of courses and programs. Examples of subjects included in this category are discussions of methodology, budgeting, nonprofit, and policy-making in courses or programs. This category also included articles on training programs, core competencies, and undergraduate education. Four, Learning Materials are academic learning tools. Examples of subjects included in this category are web tools and tests. Five, assessments are direct and indirect measures of assessment. Examples of subjects included in this category are learning outcomes, focus groups, surveys, and student evaluations.

Next, JPAE was selected for evaluation since it is the leading public administration publication that is dedicated to the scholarship of teaching and learning. The publisher, the Network of Schools of Public Policy, Affairs, and Administration (NASPAA, 2015), states,

The Journal of Public Affairs Education (JPAE) is dedicated to advancing teaching and learning in public affairs, which includes the fields of public policy analysis, public administration, and public management...The quarterly journal features peer-reviewed scholarly articles on pedagogical, curricular, and accreditation issues pertaining to public affairs education, commentaries and symposia and book reviews. (para. 14)

Abstracts from 2009-2013 were chosen since the emphasis is on current trends. A total of 149 abstracts were published during this time period.

The investigators categorized abstracts from 2009-2013 from The Journal of Public Affairs Education into the categories listed above (Instructional Approaches/Pedagogy, Learning Processes, Curricula, Learning Materials, Assessments, and Other). The investigators individually classified the subject matter of the abstracts, and they noted current trends in each area. The investigators then met to reconcile their findings. Their initial rate of agreement was $54 \%$. The low level of initial agreement may be traced to a number of factors. One of the primary reasons is that the definitions for each category were not determined in advance, but evolved during the classification process. Additionally, the categories of learning processes and learning materials are connected to the implementation of instructional approaches/pedagogy. As a result, learning process and learning materials may be classified as subcategories of instructional approaches/pedagogy or collapsed into one instructional approaches/pedagogy category. Likewise, curriculum and assessment are difficult to separate in both definition and practice. Assessment and curriculum often go hand and hand, especially relative to accreditation, both driving, informing, and affecting one another. After discussion and debate, the investigators came to agreement on $100 \%$ of the abstracts. The results reflect this agreement.

Finally, in an attempt to overcome the limitation of using one journal for the study, the researchers also reviewed the American Society of Public Administration National Conference Programs (2009-2013) to determine if trends regarding SoTL were evident in the presentation abstracts. These presentation abstracts were searched for the terms "teaching" and "learning." Each program contained a maximum of two presentation abstracts containing these words. The vast majority of presentations did not have abstracts. Due to the small number of relevant abstracts, the researchers did not classify the articles using the categories listed above and did not include the findings. However, this examination of the conference abstracts does imply that SoTL may still be struggling for acceptance by academics and practitioners in the discipline. 


\section{Results}

The coding of the 149 journal abstracts resulted in the identification of six categories by the researchers. Description findings for each category are presented in the subsequent paragraphs.

Instructional Approaches/Pedagogy: Thirty percent $(n=44)$ of the abstracts emphasized instructional approaches or pedagogy. The peak years for articles on instructional approaches or pedagogy were 2009 (14 abstracts) and 2012 (16 abstracts). The emerging trends in this area include distance learning (online) and technology strategies, including often overlapping applications, and also experiential/service learning.

Learning Processes: Only one percent $(n=2)$ of the abstracts focused on learning processes. Due to the small number of abstracts, there are no emerging trends.

Curricula: Thirty-four percent $(n=51)$ of the abstracts examined curriculum. Articles on curriculum were at their peak in 2010 and 2011. The emerging trends in this area include enhancing both the public budget/finance and non-profit curriculum, partnerships with local government, and comparative analysis of international programs and institutes.

Learning Materials: Three percent $(n=5)$ of the abstracts discussed learning materials. As with learning processes, emerging trends cannot be reported.

Assessments: Nine percent $(n=13)$ of the abstracts featured assessment. The number of articles was fairly evenly distributed over the five year period with two to four articles published on assessment each year. There are no clear emerging trends in this area, only various forms of evaluation.

Other: Twenty-three percent $(n=34)$ of the articles were on topics not included in the classification system. The "other" topics were fairly evenly distributed with five to eight articles on "other" topics each year. The emerging trends in this area include exploration and impact of culture and social class, both domestically and globally. See Figures 1 and 2 for visual display of these categories across the five conference years.

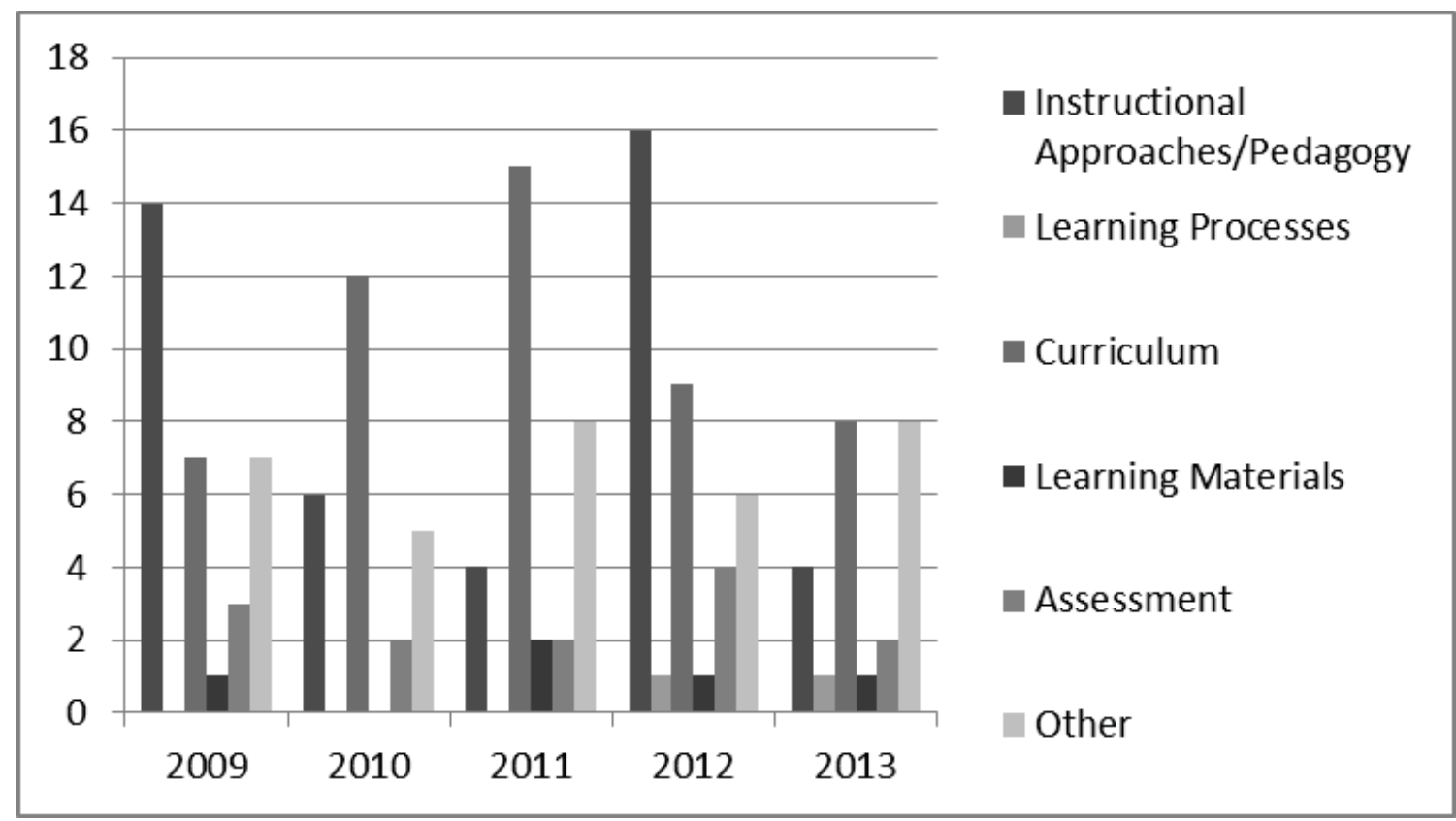

Figure 1. Frequency of content categories identified within each the conference programs from 2009 to 2013. 


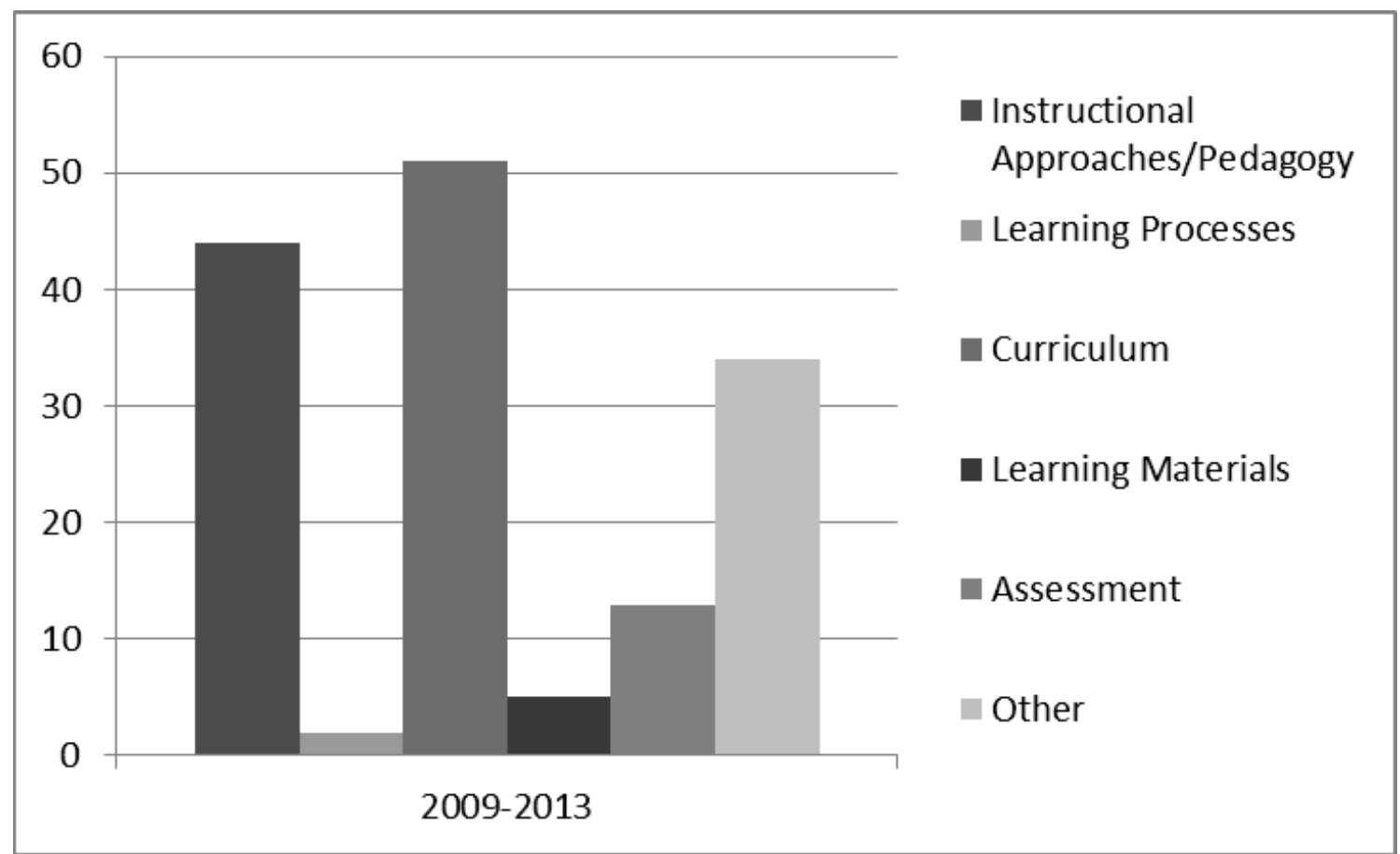

Figure 2. Five-year frequency aggregate of journal articles across each of the classification categories.

\section{Discussion}

\section{Limitations}

There are a number of limitations to this study. One significant limitation is that only one journal was used for evaluation, and there is the possibility of editorial bias. During this time period, articles in JPAE ranged from only two to over ten per issue, which could indicate a lack of submissions and/or theming of articles at times. Further, for this research, the classification of the abstracts into each of the identified categories is considered to reflect the intent of the author(s). This intent may or may not match the actual article. Abstracts were the sole basis for debate and classification. Finally, as a case study, the findings are not intended to be generalizable, but simply provide lessons learned. However, researchers could attempt to utilize similar methodology in examining other disciplines, including the possible academic-professional dichotomy, through individual discipline specific SoTL journals. The University of Central Florida's Faculty Center for Teaching and Learning (FCTL) currently provides a comprehensive list of discipline SoTL journals.

\section{Conclusions}

The data demonstrate that the focus of SoTL in public administration from 2009-2013 was on instructional approaches/pedagogy, curricula, and "other" topics. Attention was given to learning processes, learning materials, and assessments, but these areas were not as significantly represented. The findings reveal that the applied nature and interdisciplinary aspects of public administration influenced SoTL in the field.

In the area of instructional approaches, the data show an emphasis on service learning and various forms of experiential learning, including community partnerships, case studies, role playing and simulations. These findings are not surprising. The discipline of public administration embraces both theory and practice, and the instructional approaches reflect the desire to connect the two. For example, as explained by Dicke, Dowden, and Torres (2004), the goals of service learning complement the mission of many graduate public administration programs 
since both promote civic engagement, political activism, and a commitment to the public interest. The emphasis on applied learning in the abstracts indicates that public administration faculty are concerned with "the promotion of democracy and the solving of real-world problems" (Bryer, 2011, p. 91), and they want to integrate these objectives into the curriculum.

In the area of curricula, curriculum is increasingly informed by the primary accrediting body in the field, NASPAA, which also publishes JPAE. JPAE is also the journal of the ASPA's Section on Public Administration Education. ASPA (2015) "is the largest and most prominent professional association for public administration. It is dedicated to advancing the art, science, teaching and practice of public and non-profit administration" (para. 1). Thus, Public Administration programs are analyzing, debating, and changing curriculum. Further, the curricula trends of public budget/finance and non-profit curriculum indicate that the discipline is still trying to define itself, both academically and professionally.

In the category of "other", the trends demonstrate an emphasis on the impact of culture and social class, both domestically and globally. As programs become more global in nature, their curriculum, workforce development, and student population will all become more diverse. This diversity will influence the program missions, learning outcomes, and goals.

As this analysis demonstrates, public administration's interdisciplinary character causes it to struggle to become recognized as a profession. The discipline's applied nature has also influenced the degree to which it has accepted SoTL and the form that SoTL has taken within the discipline. SoTL within public administration truly reflects the discipline's debates, heritage, struggles, and characteristics. An interdisciplinary character, a drive for professionalism, and the desire to connect theory to practice, however, are not unique to public administration. These characteristics are shared by other disciplines such as criminal justice and social work, and these features may arguably provide insight into the possible directions that SoTL may take in these fields.

Rather than generalizing and assuming patterns, however, value exists to discipline-specific examinations of how distinctive disciplinary features may influence the acceptance and type of SoTL in a field. Quinnell, Russell, Thompson, Marshall, and Cowley (2010) argue that academics should explore how their home disciplines constrain the manner in which they interface with the SoTL. They suggest that the "intrinsic natures" (p. 24) of some disciplines as well as their views on what is accepted as "valid evidence" (Quinnell et al., 2010, p. 23) in scholarship may influence their SoTL.

Because of disciplinary peculiarities, it is feasible that a general characteristic that is shared by two different disciplines may actually have different effects on SoTL in an area. For example, it is argued in this paper that the interdisciplinary character of public administration contributed to its search for identity and legitimacy. This disciplinary ambiguity may have constrained the acceptance of SoTL and may have influenced the form SoTL has taken in the discipline of Public Administration. At least one communications scholar, however, believes that communications' interdisciplinary nature is a strength that may help its scholars "be major players in the SoTL movement" (Pope-Ruark, 2012, p. 362). In other words, the same characteristic-interdisciplinarity may be viewed as an obstacle to SoTL or an opportunity for SoTL, depending upon the discipline.

Generic elements of SoTL may cross disciplinary boundaries, and institutional cultures may have significant influence over departmental perceptions of research (Lee, 2007), but this paper argues that academic disciplines have a role to play in determining the degree to which SoTL is accepted and the form it takes. This case study indicates that a discipline's history and character may provide insight into its level of acceptance of SoTL. It also suggests that disciplines may be well served by examining the scholarship of teaching and learning that is currently being produced to assess if it reflects historical biases. Historical biases may limit their exploration of other relevant areas of SoTL inquiry. 


\section{References}

American Society of Public Administration. (2015). About ASPA. Retrieved from http://www. aspanet. org/public/ASPA/Abou t_ASPA/ASPA/About_ASPA/About_ASPA.as px?hkey=1cda369e-a070-48a6-a661$965 \mathrm{c} 2 \mathrm{~cd} 3 \mathrm{~d} 2 \mathrm{~d} 0$

American Society of Public Administration National Conference Programs. (20092013). Presentation abstracts.

Bilimoria, D., \& Fukami, C. (2002). The scholarship of teaching and learning in the management sciences: Disciplinary style and content. In M. T. Huber \& S. P. Morreale (Eds.), Disciplinary styles in the scholarship of teaching and learning: Exploring common ground (pp. 125-142). Washington, DC: American Association for Higher Education and the Carnegie Foundation for the Advancement of Teaching.

Bryer, T. A. (2011). Linking students with community in collaborative governance: A report on a service-learning class. Journal of Public Affairs Education, 17(1), 89-114. Retrieved from http://www. naspaa.org/J PAEMessenger/Ar ticle/VOL17-1/08_17n01_Bryer.pdf

Clarke, S. E., Hutchings, P., Keeter, S., Reeher, G., Alex-Assensoh, Y., \& Boyd, F. (2002). Transcript: Roundtable on the scholarship of teaching and learning in political science. PS: Political Science and Politics, 35(2), 223-228. Retrieved from http://www.jstor.org/stable/1554723

Dicke, L., Dowden, S., \& Torres, J. (2004). Successful service learning: A matter of ideology. Journal of Public Affairs Education, 10(3), 199-208. Retrieved from http://www. naspaa.org/J PAEMessenger/Ba cklssues.asp

Fry, B. R., \& Raadschelders, J. (2014). Mastering public administration from Max Weber to Dwight Waldo (3rd ed.). Los Angeles, CA: Sage.
Goodin, R. E., \& Klingemann, H. D. (1996). Political science: The discipline. In R. E. Goodin \& HansDieter Klingemann (Eds.), The new handbook of political science (pp. 349). New York, NY: Oxford University Press.

Hamann, K., Pollock, P. H., \& Wilson, B. M. (2009). Who SoTLs where? Publishing the scholarship of teaching and learning in political science. PS: Political Science and Politics, 42(4), 729-735. Retrieved from http://www.jstor.org/stable/ 40646679

Huber, M. T., \& Morreale, S. P. (2002). Situating the scholarship of teaching and learning: A crossdisciplinary conversation. In M. T. Huber \& S. P. Morreale (Eds.), Disciplinary styles in the scholarship of teaching and learning: Exploring common ground (pp. 1-24). Washington, DC: American Association for Higher Education and the Carnegie Foundation for the Advancement of Teaching.

Journal of Public Affairs Education. (2009-2013). Abstracts. Retrieved from

http://www. naspaa.org/J PAEMesseng er/Backlssues.asp

Lee, J. J. (2007). The shaping of departmental culture: Measuring the relative influences of the institution and discipline. Journal of Higher Education Policy and Management, 29(1), 41-55.

doi: $10.1080 / 13600800601175771$

McKinney, K. (2013). Introduction of SOTL in and cross the disciplines. In K. McKinney (Ed.), The scholarship of teaching and learning in and across the disciplines (pp. 1-11). Bloomington, IN: Indiana University Press. 
Network of schools of public policy, affairs, and administration. (2015). Journal of Public Affairs EducationNASPAA. The Global Standard in Public Service Education. Retrieved from http://www.naspaa.org/initiatives/jpae/j pae.asp

Pope-Ruark, R. (2012). Back to our roots: An invitation to strengthen disciplinary arguments via the scholarship of teaching and learning. Business Communication Quarterly, 75(4), 357-376.

doi: $10.1177 / 1080569912461051$

Quinnell, R., Russell, C., Thompson, R., Marshall, N., \& Cowley, J. (2010). Evidence-based narratives to reconcile teaching practices in academic disciplines with the scholarship of teaching and learning. Journal of the Scholarship of Teaching and Learning, 10(3), 20-30. Retrieved from http: //josotl.indiana.edu/

Rutgers, M. R. (2010). Theory and scope of public administration: An introduction to the study's epistemology. Retrieved from

http://www. aspanet.org/public/aspadocs / par/fpa/fpa-theory-article.pdf
Shafritz, J. M., Russell, E. W., \& Borick, C. P. (2013). Introducing public administration (8th ed.). Upper Saddle River, $\mathrm{NJ}$ : Pearson.

University of Central Florida. (2004). The definition of SoTL. Retrieved from http: //www.fctl.ucf.edu/ResearchAndSch olarship/SoTL/whatl sSOTL/content/Defin itions.pdf

University of Queensland. (n.d.). Scholarship of teaching and learning. Defining the scholarship of teaching at UQ. Retrieved from http://www. tedi.uq.edu.au/sotl

Waldo, D. (1984). The administrative state ( 2 nd ed.). New York, NY: Holmes and Meier Publishers.

Witman, P. D., \& Richlin, L. (2007). The status of the scholarship of teaching and learning in the discipline. International Journal for the Scholarship of Teaching and Learning, 1(1). Retrieved from http://digitalcommons. georgiasouthern. edu/ij-sotl/vol1/iss1/14

Yin, R. K. (2003). Case study research: Designs and methods (3rd ed.). Applied Social Research Methods Series: Vol. 5. Thousand Oaks, CA: Sage.

Rebekkah Stuteville is an associate professor of public administration and associate vice president for academic affairs at Park University. She earned her PhD from the University of Missouri-Kansas City. She has published in the International Journal of Organizational Analysis and the Lournal of Public Affairs Education.

Eric Click is an associate professor of public administration and program coordinator of public administration at Park University. He earned his PhD from the University of Texas-Dallas. He has published in Public Integrity and the Missouri Policy lournal. 